\title{
FRANÇOIS GUILLAUME DUCRAY-DUMINIL, Victor ou l'Enfant de la forêt
}

\section{Regina Bochenek-Franczakowa}

\section{(2) OpenEdition}

\section{Journals}

Édition électronique

URL : https://journals.openedition.org/studifrancesi/43948

DOI : $10.4000 /$ studifrancesi.43948

ISSN : 2427-5856

Éditeur

Rosenberg \& Sellier

\section{Édition imprimée}

Date de publication : 1 juin 2021

Pagination : 222

ISSN : 0039-2944

\section{Référence électronique}

Regina Bochenek-Franczakowa, « François guillaume ducray-duminil, Victor ou l'Enfant de la forêt », Studi Francesi [En ligne], 193 (LXV | I) | 2021, mis en ligne le 01 juillet 2021, consulté le 15 octobre 2022. URL : http://journals.openedition.org/studifrancesi/43948 ; DOI : https://doi.org/10.4000/ studifrancesi.43948

Ce document a été généré automatiquement le 15 octobre 2022

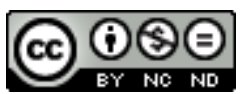

Creative Commons - Attribution - Pas d'Utilisation Commerciale - Pas de Modification 4.0 International - CC BY-NC-ND 4.0

https://creativecommons.org/licenses/by-nc-nd/4.0/ 


\title{
FRANÇOIS GUILLAUME DUCRAY-DUMINIL, Victor ou l'Enfant de la forêt
}

\author{
Regina Bochenek-Franczakowa
}

\section{RÉFÉRENCE}

FRANÇOIS GUILLAUME DUCRAY-DUMINIL, Victor ou l'Enfant de la forêt, éd. Ł. Szkopiński, Paris, Classiques Garnier, 2019, 505 pp.

1 Ducray-Duminil, auteur prolifique de la fin du XVIII ${ }^{e}$ siècle, restait longtemps dans les marges de l'histoire littéraire. Ses romans, populaires jusqu'au milieu du XIX ${ }^{e}$ siècle, trouvaient un public diversifié, non limité à la jeunesse, à l'encontre de ce qu'on a estimé plus tard. Łukasz Szkopiński, auteur de la première monographie sur l'œuvre entière de l'écrivain, a eu raison de choisir ce roman pour le rappeler au lecteur moderne. D'abord, Victor ou l'Enfant de la forêt, publié en 1797, best-seller à son époque, souvent réédité, adapté au théâtre et traduit en plusieurs langues, était en lui-même un phénomène particulier: tradition vivante, quand on pense au scénario du film de Pierre Caussade, transcrit du tapuscrit et publié dans ce volume en Annexe (pp. 479-490). Pourtant, ce qui intéresse maintenant dans cette œuvre, c'est sa dimension idéologique. Paru bientôt après la Terreur jacobine, ce roman s'est inscrit dans la vague des récits où les auteurs essayaient de comprendre ce qui s'est passé en France. Dans l'Introduction, Szkopiński attire notre attention sur l'attitude modérée de l'écrivain envers la Révolution. Il met aussi en relief le personnage du «superbe Roger», père du vertueux Victor, qui se distingue de tous les autres personnages de Ducray-Duminil par son caractère ambigu: orgueilleux, fier, indépendant - et à la fois bandit, hors-la-loi, cruel, immoral. Aux yeux de Szkopiński, ce personnage et sa communauté des Indépendants renvoient à la situation politique de la Terreur. La métaphore révolutionnaire, outre sa fonction cathartique, avait à montrer aux lecteurs que, une fois les débordements finis, la société allait retrouver sa stabilité d'autrefois. La lecture de Victor est fort instructive pour tous ceux qui s'intéressent au développement du roman au Tournant des 
Lumières. On y retrouve les motifs et topoï du roman noir et du roman d'aventures, subordonnés au message didactique et édifiant. En même temps la narration, d'un ton de causerie amicale avec le lecteur et jalonnée de nombreux points de suspension (l'éditeur a bien fait de garder ce trait de la ponctuation), ainsi que l'atmosphère de mystère, quelques décors, paysages et événements, tout cela rappelle vaguement certains traits des romans de Victor Hugo, Balzac ou George Sand. La dette des écrivains romantiques envers Ducray-Duminil, qu'ils se sont bien gardés de reconnaître, semble transparaître à travers Victor ou l'Enfant de la forêt. 